\section{ELUCIDATION OF A TRIPARTITE MECHANISM UNDERLYING THE IMPROVEMENT IN CARDIAC TOLERANCE TO ISCHEMIA BY COENZYME $a_{10}$ PRETREATMENT}

Coenzyme $Q_{10}$, which is involved in mitochondrial adenosine triphosphate production, is also a powerful antioxidant. We hypothesize that coenzyme $Q_{10}$ pretreatment protects myocardium from ischemia reperfusion injury both by its ability to increase aerobic energy production and by protecting creatine kinase from oxidative inactivation during reperfusion. Isolated hearts (six per group) from rats pretreated with either coenzyme $Q_{10}, 20 \mathrm{mg} / \mathrm{kg}$ intramuscularly and $10 \mathrm{mg} / \mathrm{kg}$ intraperitoneally (treatment) or vehicle only (control) 24 and 2 hours before the experiment were subjected to 15 minutes of equilibration, 25 minutes of ischemia, and 40 minutes of reperfusion. Developed pressure, contractility, compliance, myocardial oxygen consumption, and myocardial aerobic efficiency were measured. Phosphorus 31 nuclear magnetic resonance $\left({ }^{31}\right.$ P-NMR) spectroscopy was used to determine adenosine triphosphate and phosphocreatine concentrations as a percentage of a methylene diphosphonic acid standard. Hearts were assayed for myocardial coenzyme $Q_{10}$ and myocardial creatine kinase activity at end equilibration and at reperfusion. Treated hearts showed higher myocardial coenzyme $Q_{10}$ levels $(133 \pm 5 \mu \mathrm{g} / \mathrm{gm}$ ventricle versus $117 \pm 4 \mu \mathrm{g} / \mathrm{gm}$ ventricle, $p<0.05)$. Developed pressure at end reperfusion was $62 \% \pm 2 \%$ of equilibration in treatment group versus $37 \% \pm 2 \%$ in control group, $p<\mathbf{0 . 0 0 5}$. Preischemic myocardial aerobic efficiency was preserved during reperfusion in treatment group $(0.84 \pm 0.08$

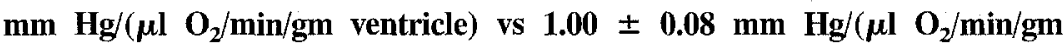
ventricle) at equilibration, $p=$ not significant), whereas in the control group it fell to $0.62 \pm 0.07 \mathrm{~mm} \mathrm{Hg} /(\mu \mathrm{l} \mathrm{O} / \mathrm{min} / \mathrm{gm}$ ventricle, $p<0.05$ vs equilibration and vs the treatment group at reperfusion. Treated hearts showed higher adenosine triphosphate and phosphocreatine levels during both equilibration (adenosine triphosphate $49 \% \pm 2 \%$ for the treatment group vs $33 \% \pm 3 \%$ in the control group, $p<0.005$; phosphocreatine $49 \% \pm 3 \%$ in the treatment group vs $35 \% \pm 3 \%$ in the control group, $p<0.005$ ) and reperfusion (adenosine triphosphate $18 \% \pm 3 \%$ in the treatment group vs $11 \% \pm 2 \%$ in the control group, CTRL $p<0.05$; phosphocreatine $45 \% \pm 2 \%$ in the treatment group vs $23 \% \pm 3 \%$ in the control group, $p<0.005$ ). Creatine kinase activity in treated hearts at end reperfusion was $74 \% \pm 3 \%$ of equilibration activity vs $65 \% \pm 2 \%$ in the control group, $p<0.05$ ). Coenzyme $Q_{10}$ pretreatment improves myocardial function after ischemia and reperfusion. This results from a tripartite effect: (1) higher concentration of adenosine triphosphate and phosphocreatine, initially and during reperfusion, (2) improved myocardial aerobic efficiency during reperfusion, and (3) protection of creatine kinase from oxidative inactivation during reperfusion. (J THORAC Cardiovasc SuRG 1996;111:443-50)

Juan A. Crestanello, MD (by invitation), Joseph Kamelgard, MD (by invitation), David M. Lingle, MD (by invitation), Svend A. Mortensen, MD (by invitation), Morten Rhode (by invitation), and

Glenn J. R. Whitman, MD, Philadelphia, Pa., and Copenhagen, Denmark
From the Division of Cardiothoracic Surgery, The Medical College of Pennsylvania, Philadelphia, and The National University Hospital (Rigshospitalet), Copenhagen.

Supported by the National Institutes of Health grant HL 42922.

Read at the Seventy-fifth Annual Meeting of The American Association for Thoracic Surgery, Boston, Mass., April 23-26, 1995.
Address for reprints: Juan A. Crestanello, MD, Division of Cardiothoracic Surgery, The Medical College of Pennsylvania, 3300 Henry Ave., Philadelphia, PA 19129.

Copyright (C) 1996 by Mosby-Year Book, Inc.

$0022-5223 / 96 \$ 5.00+0 \quad \mathbf{1 2 / 6 / 7 0 1 3 6}$ 
$\mathrm{M}^{\mathrm{s}}$ yocardial ischemia-reperfusion injury is associated with toxic oxygen metabolite production that causes lipid and protein peroxidation and energetic derangements as a result of alterations in energy synthesis, transfer, or use ${ }^{1-5}$ Oxygen radical scavengers and agents that modulate energy use and production have been used to prevent or attenuate this injury. ${ }^{6-10}$ Coenzyme $Q_{10}\left(\mathrm{CoQ}_{10}\right)$ has both of these properties. ${ }^{11}$

$\mathrm{COQ}_{10}$ is a lipid-soluble benzoquinone that has properties potentially useful in preventing or attenuating the damage associated with ischemia and reperfusion. ${ }^{11,12} \mathrm{CoQ}_{10}$ is directly involved in energy transduction and aerobic adenosine triphosphate (ATP) production; it transports electrons in the respiratory chain and couples the respiratory chain to oxidative phosphorylation. ${ }^{13-16} \mathrm{CoQ}_{10}$ is a regenerable and powerful antioxidant, capable of protecting cell structures from oxidative damage during reperfusion. ${ }^{17-19}$ It also regenerates vitamin $\mathrm{E}$ from the tocopheroxyl radical produced by free oxygen radicals. ${ }^{17}$ The antioxidant actions of $\mathrm{CoQ}_{10}$ are not limited to the mitochondria but are applicable to any other cell membrane containing $\mathrm{CoQ}_{10}{ }^{17}$ These properties make $\mathrm{CoQ}_{10}$ an ideal therapeutic agent to reduce myocardial ischemia-reperfusion injury. ${ }^{20-22}$

Creatine kinase (CK) is a crucial enzyme involved in the metabolism of high-energy phosphates. CK is exquisitely sensitive to oxidation and has been shown to be susceptible to inactivation by toxic oxygen metabolites during reperfusion, impairing the transfer of high-energy phosphates between phosphocreatine and adenosine diphosphate. $^{4,5,23,24}$ We hypothesized that $\mathrm{CoQ}_{10}$ pretreatment protects myocardium from ischemia reperfusion injury by increasing aerobic energy production and by protecting $\mathrm{CK}$ from oxidative inactivation during reperfusion.

\section{Method}

Pretreatment with $\mathrm{CoQ}_{10}$. Male Sprague-Dawley rats weighing 200 to $250 \mathrm{gm}$ (six per group) were divided into two groups. The $\mathrm{CoQ}_{10}$ group was pretreated with $\mathrm{CoQ}_{10}$ (20 mg/kg intramuscularly and $10 \mathrm{mg} / \mathrm{kg}$ intraperitoneally; Pharma Nord, Vojens, Denmark), control group was pretreated with vehicle only (dimethyl sulfoxide, Sigma Chemical Co., St. Louis, Mo.); both groups underwent pretreatment 24 hours and 2 hours before the experiment.

Isolated heart preparation. Rats were anesthetized with sodium pentobarbital $(60 \mathrm{mg} / \mathrm{kg}$ intraperitoneally) and heparin sodium (500 IU intraperitoneally) in accordance with the "Principles of Laboratory Animal Care" formulated by the National Society for Medical Research and the "Guide for the Care and Use of Laboratory Animals" prepared by the Institute of Laboratory Animal Resources and published by the National Institutes of Health (NIH Publication No. 86-23, revised 1985). Hearts were excised quickly and arrested in a $4^{\circ} \mathrm{C}$ Krebs-Henseleit solution of the following composition: sodium chloride, $118 \mathrm{mmol} / \mathrm{L}$; potassium chloride, $4.6 \mathrm{mmol} / \mathrm{L}$; potassium phosphate, $1.17 \mathrm{mmol} / \mathrm{L}$; magnesium sulfate, 1.17 $\mathrm{mmol} / \mathrm{L}$; calcium chloride, $1.16 \mathrm{mmol} / \mathrm{L}$; sodium bicarbonate, $23 \mathrm{mmol} / \mathrm{L}$; and glucose, $5.3 \mathrm{mmol} / \mathrm{L}$. The hearts were then transferred to a nonrecirculating Langendorff apparatus and perfused at a constant aortic pressure of $76 \mathrm{~mm}$ $\mathrm{Hg}$ at $37^{\circ} \mathrm{C}$ with Krebs-Henseleit solution ( $\mathrm{pH} 7.4$, oxygen tension $>500 \mathrm{~mm} \mathrm{Hg}$ ), previously equilibrated with a gas mixture of $92.5 \%$ oxygen and $7.5 \%$ carbon dioxide. Hearts were paced at 360 beats/min at two times threshold (Grass Instrument Co., Quincy, Mass.). An intraventricular latex balloon was inserted in the left ventricle through the mitral valve and attached to a pressure transducer (COBE Laboratories, Inc., Lakewood, Colo.). Left ventricular end-diastolic pressure was set at $6 \mathrm{~mm} \mathrm{Hg}$. Developed pressure (DP; peak systolic pressure minus end-diastolic pressure), contractility $(+\mathrm{dP} / \mathrm{dt})$, and compliance $(-\mathrm{dP} / \mathrm{dt})$ were recorded throughout the experiment. Coronary flow was measured by a digital flow meter (Humonics, Rancho Cordova, Calif.) by measuring pulmonary artery effluent. Data were amplified, acquired, and recorded on a Macintosh IIci computer (Apple Computer, Inc., Cupertino, Calif.) with LabView software (National Instruments, Austin, Texas).

Experimental protocol. Hearts were subjected to 15 minutes of equilibration, 25 minutes of global normothermic ischemia, and 40 minutes of reperfusion. Ischemia was achieved by means of a stopcock at the level of the aortic root. Pacing was halted during ischemia, and heart temperature was maintained at $37^{\circ} \mathrm{C}$ by immersion in a water-jacketed, nongassed perfusate bath.

Determination of myocardial oxygen consumption $\left(\mathrm{MVO}_{2}\right)$ and myocardial aerobic efficiency $\left(\mathrm{DP} / \mathrm{MVo}_{2}\right)$. At end-equilibration and at end-reperfusion, oxygen tension was determined with a blood gas analyzer (Corning-170 pH/Blood Gas Analyzer; Corning Inc., Medfield, Mass:) from perfusate samples drawn from the aortic cannula and from the coronary sinus. $\mathrm{MVO}_{2}(\mu \mathrm{l} \mathrm{O} / \mathrm{min} / \mathrm{gm}$ ventricle, wet weight) was determined from the following formula:

$\mathrm{MVO}_{2}=\left(\right.$ Solubility of oxygen at $\left.37^{\circ} \mathrm{C}\right) \times\left(p_{a} \mathrm{O}_{2}-p_{c s} \mathrm{O}_{2}\right)$

$\times C F /$ Wet weight of ventricle.

where $p_{a} O_{2}$ represents oxygen tension determined from perfusate drawn from the aortic cannula, $\mathrm{p}_{c s} \mathrm{O}_{2}$ represents oxygen tension in perfusate drawn from the coronary sinus, and $C F$ represents coronary flow. $\mathrm{DP} / \mathrm{MVO}_{2}$ was defined as the ratio between DP (in millimeters of mercury) and $\mathrm{MVO}_{2}$.

Determination of $\mathrm{CK}$ activity in heart tissue. Control and $\mathrm{CoQ}_{10}$ hearts (six per group) were perfused for 15 minutes to determine baseline (preischemic) CK activity. After ischemia at the end of the 40 minutes of reperfusion, left and right ventricles were freeze clamped in liquid nitrogen and stored at $-70^{\circ} \mathrm{C}$. Tissue samples were 


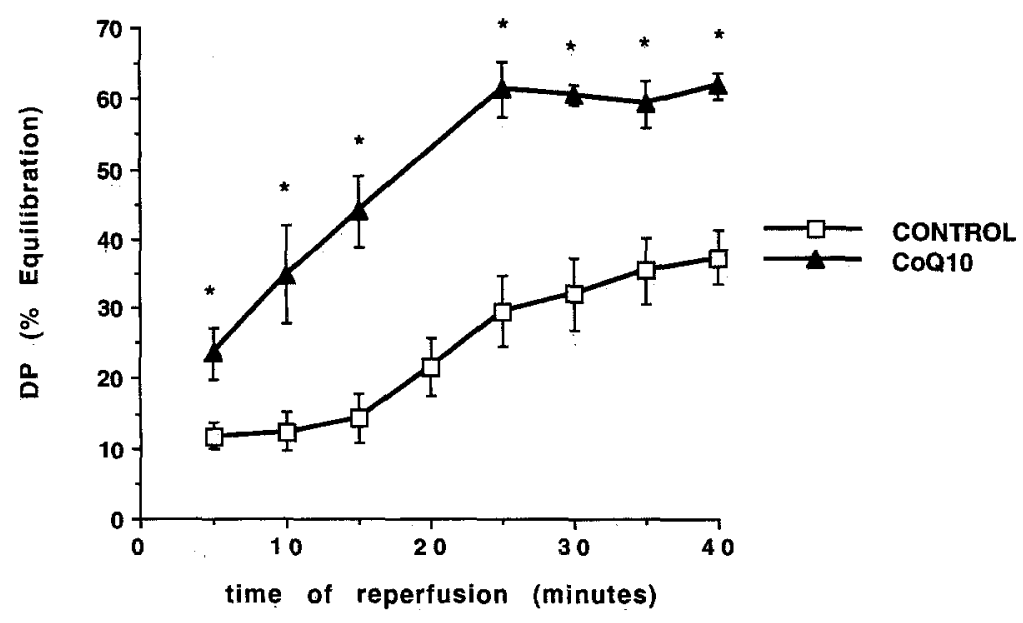

Fig. 1. Recovery of mechanical function during reperfusion expressed as a percentage of end-equilibration left ventricular DP. Asterisk indicates $p<0.005$ versus control. Note improvement afforded by $\operatorname{CoQ}_{10}$ pretreatment.

weighed, placed in 10 volumes/weight of cold isolation buffer $(5 \mathrm{mmol} / \mathrm{L}$ potassium phosphate, $0.3 \mathrm{~mol} / \mathrm{L}$ sucrose, $5 \mathrm{mmol} / \mathrm{L}$ morpholino propanesulfonic acid and 0.2 $\mathrm{mmol} / \mathrm{L}$ ethylenediamintetraacetic acid, $\mathrm{pH} 7.4$ ), and homogenized at $4^{\circ} \mathrm{C}$ during 20 seconds with a Tekmar Tissumizer (Tekmar Co., Cincinnati, Ohio). Homogenates were centrifuged at $0^{\circ} \mathrm{C}$ for 10 minutes at $2000 \mathrm{~g}$. The supernatant was diluted to less than $1000 \mathrm{IU} / \mathrm{L}$ before assay of CK activity. The assay was performed with Sigma diagnostic kit no. 47 UV (Sigma Chemical Co.) on a Beckman DU 640 spectrophotometer (Beckman Instruments, Inc., Fullerton, Calif.) in quartz cuvettes maintained at $30^{\circ} \mathrm{C}$. Values were expressed as international units per gram of ventricle.

Determination of preischemic $\mathrm{CoQ}_{10}$ concentrations in heart tissue. Control and $\mathrm{CoQ}_{10}$ hearts (six per group) were perfused for 15 minutes. Hearts were freeze clamped in liquid nitrogen and stored at $-70^{\circ} \mathrm{C}$. $\mathrm{CoQ}_{10}$ levels were determined according to the procedure described by Edlund. ${ }^{25}$ Briefly, tissue samples were homogenized partly enzymatically (with collagenase in ultrabath) and partly mechanically. After extraction with 1-propanol and the addition of an internal standard (coenzyme $\mathrm{Q}_{11}$ ), the residue was subjected to high performance liquid chromatography with electrochemical detection, yielding the total tissue content of both $\mathrm{CoQ}_{10}$ and coenzyme $Q_{9}$. Levels are expressed as micrograms per gram of dry ventricle.

Evaluation of high-energy phosphate metabolites. Parallel groups of hearts (six per group) were perfused according to the previously described protocol within a 11.5 Tesla Bruker AM 500 spectrometer (Bruker Medical Instruments, Inc., Billerica, Mass.) and phosphorus 31 nuclear magnetic resonance ( $\left.{ }^{31} \mathrm{P}-\mathrm{NMR}\right)$ spectra were acquired. A capillary tube with a standard concentration of methylene diphosphonic acid (MDP) was placed next to the heart inside the NMR tube to act as an absolute standard. ${ }^{31} \mathrm{P}-\mathrm{NMR}$ spectra were obtained every $10 \mathrm{~min}-$ utes with 416 45-degree angle pulses with an interpulse delay of 1 second. A line broadening of $15 \mathrm{~Hz}$ was used.
Inorganic phosphate, phosphocreatine, ATP, and MDP areas were determined by triangulation. To correct for partial saturation, fully relaxed ${ }^{31} \mathrm{P}-\mathrm{NMR}$ spectra were obtained at a relaxation delay of 15 seconds, and correction factors for inorganic phosphate, ATP, phosphocreatine, and MDP were determined. Only the $\beta$-ATP peak was used for ATP determination because the $\alpha$ and $\gamma$ peaks contain other phosphorylated nucleotide bases. Values of inorganic phosphate, ATP, and phosphocreatine are expressed as a percentage of the MDP standard as well as in terms of the percentage of their respective preischemic levels. Intracellular $\mathrm{pH}(\mathrm{pHi})$ was determined only during ischemia from the chemical shift of inorganic phosphate relative to phosphocreatine by applying the following equation: $\mathrm{pH}_{i}=6.77-\log [(2.52 /[\mathrm{d}-3.22])-$ $1],{ }^{26,27}$ where $d$ is the chemical shift in parts per million. During equilibration and reperfusion the presence of two overlapping inorganic phosphate peaks (intracellular and buffer) made it impossible to determine the inorganic phosphate concentration and $\mathrm{pHi}$.

Statistical analysis. Data are expressed as mean \pm standard error of the mean. Paired and nonpaired $t$ tests were used for statistical significance. Significance was assumed for $p<0.05$.

\section{Results}

Mechanical function. Hearts perfused for 80 minutes of equilibration preserved $94 \% \pm 2 \%$ of their equilibration DP, justifying the stability of our model. Control and $\mathrm{CoQ}_{10}$ hearts had the same DP at end-equilibration $(109 \pm 6$ vs $107 \pm 5 \mathrm{mmHg}, \mathrm{p}=$ not significant [NS]). At end-reperfusion, $\mathrm{CoQ}_{10}$ hearts recovered $62 \% \pm 2 \%$ of their preischemic DP whereas control hearts recovered only $37 \% \pm$ $2 \%$ ( $p<0.005$ vs control, Fig. 1.) Both $+\mathrm{dP} / \mathrm{dt}$ and $-\mathrm{dP} / \mathrm{dt}$ behaved in a similar fashion. At end-reper- 


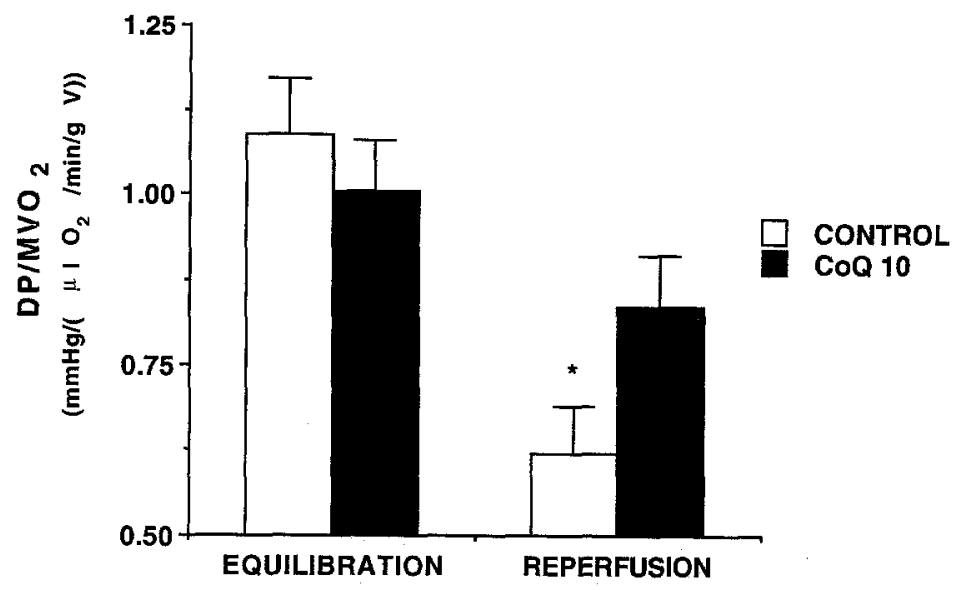

Fig. 2. $\mathrm{DP} / \mathrm{MVO}_{2}$ during equilibration and at end-reperfusion. During reperfusion $\mathrm{Co}_{10}$ hearts maintained their preischemic efficiency, in contrast to control hearts. Asterisk indicates $p<0.05$ versus $\mathrm{CoQ}_{10}$ group at reperfusion and vs both groups at equilibration. $V$, Ventricle.

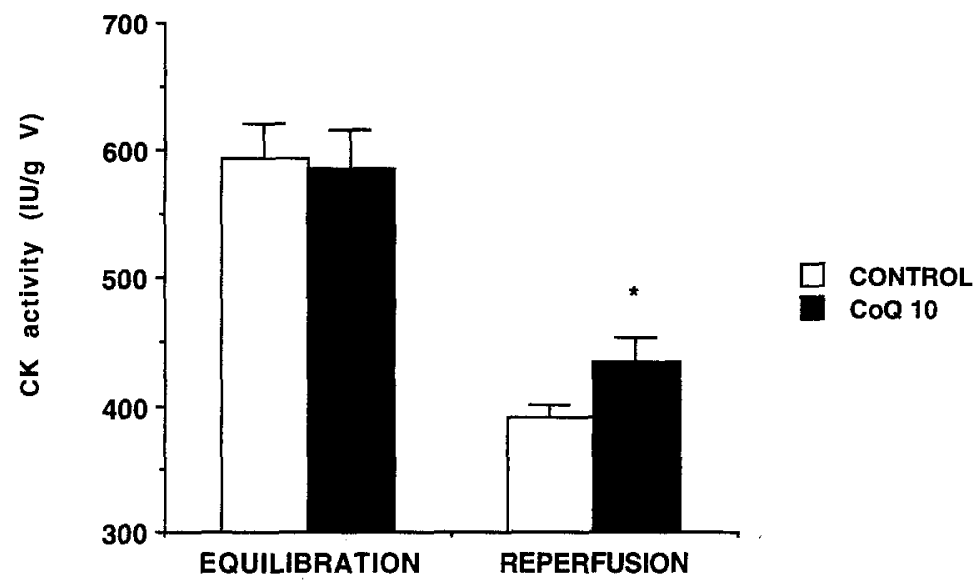

Fig. 3. Myocardial CK activity at end-equilibration and at end-reperfusion. Hearts pretreated with $\operatorname{CoQ}_{10}$ maintained greater CK activity than did control hearts. Asterisk indicates $p<0.05$ versus control at reperfusion. $V$, Ventricle.

fusion, $\mathrm{CoQ}_{10}$ hearts had lower end-diastolic pressures than did control $(40.8 \pm 2$ vs $56 \pm 4 \mathrm{~mm} \mathrm{Hg}$, $p<0.005)$. The onset of contracture during ischemia ( $7.7 \pm 0.4$ vs $8.6 \pm 0.4$ minutes, $\mathrm{p}=\mathrm{NS})$ and its degree at end-ischemia ( $44.1 \pm 2$ vs $45 \pm 1 \mathrm{~mm}$ $\mathrm{Hg}, p=\mathrm{NS}$ ) were the same in both groups.

$\mathbf{D P} / \mathbf{M V O}_{2}$. During equilibration, control and $\mathrm{CoQ}_{10}$ hearts had the same $\mathrm{DP} / \mathrm{MVO}_{2}(1.09 \pm 0.08$ $\mathrm{mm} \mathrm{Hg} /\left[\mu \mathrm{O}_{2} / \mathrm{min} / \mathrm{gm}\right.$ ventricle) vs $1.00 \pm 0.08 \mathrm{~mm}$ $\mathrm{Hg} /\left(\mu \mathrm{l} \mathrm{O}_{2} / \mathrm{min} / \mathrm{gm}\right.$ ventricle $)$. At end reperfusion, however, $\mathrm{COQ}_{10}$ hearts preserved their preischemic $\mathrm{DP} / \mathrm{MVO}_{2}\left(0.84 \pm 0.08 \mathrm{~mm} \mathrm{Hg} /\left(\mu \mathrm{O}_{2} / \mathrm{min} / \mathrm{gm}\right.\right.$ ventricle), $p=\mathrm{NS}$ vs $\mathrm{CoQ}_{10}$ at equilibration). Control $\mathrm{DP} / \mathrm{MVO}_{2}$, however, fell to $0.62 \pm 0.07 \mathrm{~mm} \mathrm{Hg} /(\mu 1$
$\mathrm{O}_{2} / \mathrm{min} / \mathrm{gm}$ ventricle), $p<0.05$ vs control at equilibration and vs $\mathrm{CoQ}_{10}$ at reperfusion (Fig. 2).

CK activity. Preischemic CK activity was unaffected by $\mathrm{CoQ}_{10}$ pretreatment $(590 \pm 29 \mathrm{IU} / \mathrm{gm}$ ventricle vs $590 \pm 26 \mathrm{IU} / \mathrm{gm}$ ventricle in control, $p=$ NS). In control hearts, CK activity after 40 minutes of reperfusion fell to $390 \pm 10 \mathrm{IU} / \mathrm{gm}$ ventricle. $\mathrm{CoQ}_{10}$ hearts, however, lost less CK activity after reperfusion ( $435 \pm 17 \mathrm{IU} / \mathrm{gm}$ ventricle, $p<0.05$ vs control during reperfusion; (Fig. 3).

Preischemic myocardial $\mathrm{CoQ}_{10}$ levels. Baseline myocardial $\mathrm{CoQ}_{10}$ levels in $\mathrm{CoQ}_{10}$ hearts averaged $133 \pm 5 \mu \mathrm{g} / \mathrm{gm}$ dry ventricle. They averaged $117 \pm 4$ $\mu \mathrm{g} / \mathrm{gm}$ dry ventricle in control hearts $(p<0.05)$. 


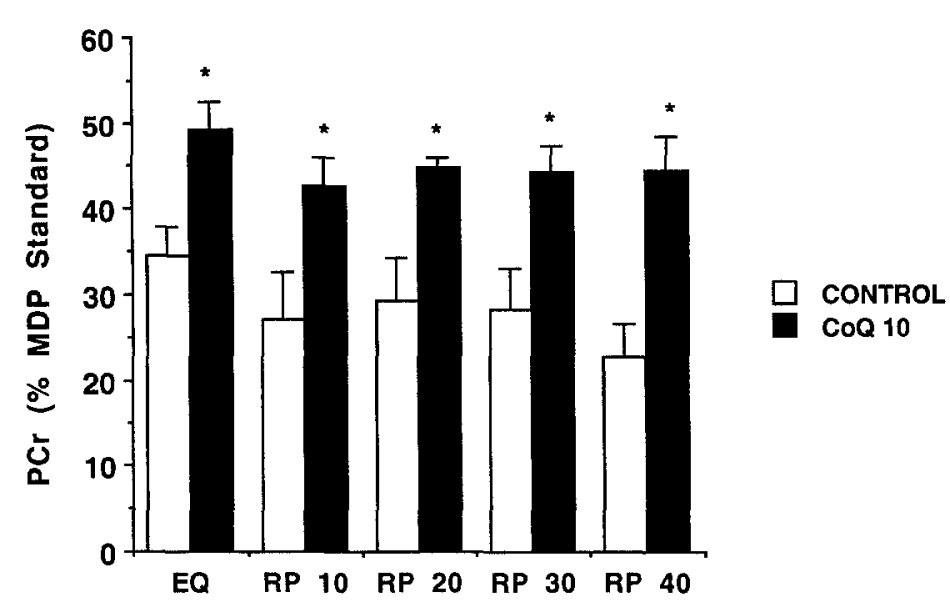

Fig. 4. Phosphocreatine $(P C r)$ levels during equilibration $(E Q)$ and during reperfusion $(R P)$. $\mathrm{CoO}_{10}$ hearts showed higher levels during both equilibration and reperfusion. Asterisk indicates $p<0.005$ versus control. Horizontal axis indicates time in minutes.

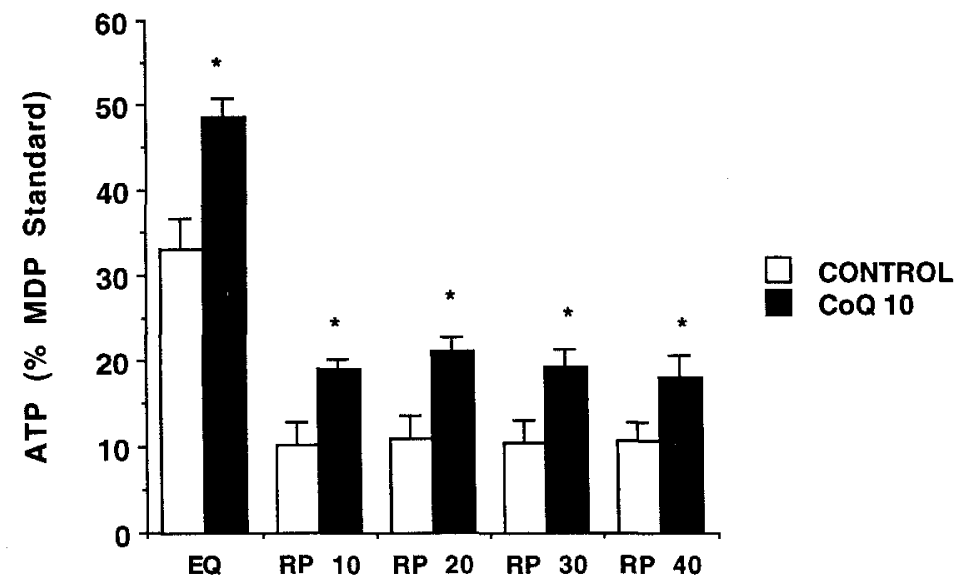

Fig. 5. ATP levels during equilibration $(E Q)$ and during reperfusion $(R P) \cdot \mathrm{CoQ}_{10}$ hearts showed higher levels during both equilibration and reperfusion. Asterisk indicates $p<0.05$ versus control. Horizontal axis indicates time in minutes.

${ }^{31}$ P-NMR. At end-equilibration, hearts pretreated with $\mathrm{CoQ}_{10}$ showed higher phosphocreatine levels than did control $(49 \% \pm 3 \%$ vs $35 \% \pm 3 \%$ MDP, $p<0.005$ ) as well as higher ATP levels $(49 \% \pm 2 \%$ vs $33 \% \pm 3 \%$ MDP, $p<0.005)$. These higher levels are maintained throughout reperfusion; by end-reperfusion, phosphocreatine levels in $\mathrm{CoQ}_{10}$ hearts were $45 \% \pm 2 \%$ versus $23 \% \pm 3 \%$ MDP in control hearts $(p<0.005)$, and ATP levels were $18 \% \pm 3 \%$ versus $11 \% \pm 2 \%$ MDP in control hearts $(p<0.05$; Fig. 4 and 5). At end-ischemia, $\mathrm{CoQ}_{10}$ and control hearts showed similar ATP levels $(10.5 \% \pm 3 \%$ vs $6.8 \% \pm 2.4 \% \mathrm{MDP}, p=\mathrm{NS})$ and similar $\mathrm{pH}_{\mathrm{i}}(6.24 \pm 0.15$ vs $6.27 \pm 0.15, p=\mathrm{NS})$. Phosphocreatine and ATP levels during reperfusion can be also expressed as a percentage of equilibration levels (phosphocreatine $92 \% \pm 7 \%$ in $\mathrm{CoQ}_{10}$ vs $66 \% \pm 8 \%$ in control, $p<0.05$; ATP $39 \% \pm 7 \%$ in $\mathrm{CoQ}_{10}$ vs $32 \% \pm 5 \%$ in control, $p=\mathrm{NS}$ ).

\section{Discussion}

This experiment shows that $\mathrm{CoQ}_{10}$ pretreatment improves myocardial tolerance to ischemia reperfusion injury. Not only does $\mathrm{CoQ}_{10}$ improve the recovery of DP, it also improves diastolic function during reperfusion, as seen by a lower $-\mathrm{dP} / \mathrm{dt}$ and a lower end-diastolic pressure.

Exogenously administered $\mathrm{CoQ}_{10}$ has been shown to nonspecifically incorporate into cell and mitochondrial membranes. ${ }^{28,29}$ We have shown an incre- 
ment in myocardial $\mathrm{CoQ}_{10}$ levels in rats pretreated with $\mathrm{CoQ}_{10}$ compared with control rats. Although $\mathrm{CoQ}_{10}$ synthesis decreases during ischemia, ${ }^{30} \mathrm{hu}$ man and animal studies have shown that $\mathrm{CoQ}_{10}$ pretreatment sufficient to increase preischemic $\mathrm{CoQ}_{10}$ levels, as in our experimental model, prevents the myocardial $\mathrm{CoQ}_{10}$ depletion that normally occurs during ischemia and reperfusion. ${ }^{30-33}$

As a member of the respiratory chain, $\mathrm{CoQ}_{10}$ is involved in the flux of electrons as well as in the coupling of the respiratory chain to oxidative phosphorylation. ${ }^{13-16} \mathrm{CoQ}_{10}$ controls the efficiency of oxidative phosphorylation. ${ }^{14}$ Exogenously administered $\mathrm{CoQ}_{10}$ appears to be able to increase the concentrations of high-energy phosphates, as shown by ATP and phosphocreatine levels during equilibration. Although this increment in high-energy phosphate levels was not translated into better mechanical function before ischemia, during reperfusion $\mathrm{CoQ}_{10}$ hearts showed not only higher phosphocreatine and ATP levels but also improved recovery of mechanical function. Although this increment in aerobic energy production compared with control hearts could be sufficient to explain the improvement in mechanical function during reperfusion, it is interesting that before ischemia the elevation in high-energy phosphate levels did not improve mechanical function. This apparent paradox is obviously not addressed by evaluation of high-energy phosphate levels alone. The increment in ATP and phosphocreatine levels seen during equilibration in $\mathrm{CoQ}_{10}$ hearts may limit myocardial damage during ischemia by better preserving cell structure and function, although our experiments were not designed to test this supposition. The observation that end-ischemic ATP levels and onset of contracture were similar in both groups is puzzling and obviously requires further investigation.

Myocardial CK, is inactivated during reperfusion by toxic oxygen metabolites, and this inactivation is directly responsible for limiting recovery of mechanical function. ${ }^{4,5,24}$ This loss of myocardial CK activity during reperfusion is the result of oxidation of its thiol groups and does not result, as we have previously shown, from washout of CK from damaged cells. ${ }^{4}$ This inactivation is responsible at least in part for lower ATP levels as a result of the impaired transfer of high-energy phosphates between phosphocreatine and adenosine diphosphate. As a result, less ATP is available to sustain myofibrillar activity. ${ }^{4}$ $\mathrm{CoQ}_{10}$ hearts showed higher CK activity as well as higher ATP levels during reperfusion, both of which are consistent with improved CK activity during reperfusion provided by $\mathrm{CoQ}_{10}$. Although the mechanism is not specifically addressed in this study, CK protection is almost certainly the result of $\mathrm{CoQ}_{10}$ antioxidant activity because oxidation is the primary mechanism for reperfusion-induced inactivation. Another mechanism that may explain higher levels of myocardial $\mathrm{CK}$ activity during reperfusion in $\mathrm{CoQ}_{10}$ hearts is the ability of $\mathrm{CoQ}_{10}$ to stabilize cell membranes. ${ }^{11}$ On the basis of the results of previous experiments in which we showed no significant increment of $\mathrm{CK}$ in the coronary effluent during reperfusion, we believe that cell membrane leakage is not responsible for loss of CK activity during reperfusion, and stabilization of cell membranes by $\mathrm{CoQ}_{10}$ is therefore not the mechanism responsible for the protection of $\mathrm{CK}$ activity during reperfusion.

Finally, $\mathrm{CoQ}_{10}$ pretreatment preserves $\mathrm{DP} / \mathrm{MVO}_{2}$ during reperfusion with respect to that in the control group. Hearts stunned by ischemia-reperfusion consume more oxygen to generate less pressure than during equilibration and are therefore less efficient. $^{34-38}$ Several authors have shown that mitochondrial function is not the limiting factor in recovery of mechanical function in stunned myocardium. ${ }^{37-40}$ Rather, alterations in electromechanical coupling, ionic transport (calcium channels, ATPdependent potassium channels), and muscle contraction are principally involved in the increased cost of contraction in the stunned myocardium with respect to $\mathrm{MVO}_{2}{ }^{41-46} \mathrm{CoQ}_{10}$ may protect reperfused myocardium through its antioxidant and membranestabilizing properties, as well as through its ability to increase ATP levels to support energy-consuming processes, allowing $\mathrm{DP} / \mathrm{MVO}_{2}$ to remain at normal levels.

\section{Conclusions}

We conclude from these experiments that $\mathrm{CoQ}_{10}$ pretreatment effectively increases myocardial $\mathrm{Co}_{10}$ levels, leading to an improved tolerance to myocardial reperfusion injury. This improvement results from the effects of $C o Q_{10}$ on mitochondrial function and antioxidant activity. $\mathrm{CoQ}_{10}$ increases myocardial energy production, protects $C K$ during reperfusion, preserves $\mathrm{DP} / \mathrm{MVO}_{2}$, and improves mechanical function after ischemic insult.

\section{REFERENCES}

1. Braunwald E, Kloner R. Myocardial reperfusion: a double-edged sword? J Clin Invest 1985;76:1713-9.

2. Goldhaber JI, Weiss J. Oxygen free radicals and cardiac 
reperfusion abnormalities. Hypertension 1982;20:118127.

3. Meerson FZ, Kagan VE. The role of lipid peroxidation in pathogenesis of ischemic damage and the antioxidant protection of the heart. Basic Res Cardiol 1982;77:465-85.

4. Banerjee A, Grosso MA, Brown J, Rogers K, Whitman GJ. Oxygen metabolite effects on creatine kinase and cardiac energetics after reperfusion. Am J Physiol 1991;261:H590-601.

5. Neubauer S, Hamman B, Perry S, Bittl J, Ingwall J. Velocity of the creatine kinase reaction decreases in postischemic myocardium: a 31PNMR magnetization transfer study of the isolated ferret heart. Circ Res 1988;63:1-15.

6. Whitman GJ, Kieval R, Brown J, Banerjee A, Grosso $M$, Harken A. Optimal hypothermic preservation of arrested myocardium in isolated perfused rabbit hearts: a 31PNMR study. Surgery 1989;105:100-5.

7. Hajime O, Englenman R, Rousou J, Breyer R, Lemeshow $\mathrm{S}$, Das D. Cardiac performance during reperfusion improved by pretreatment of oxygen free radicals scavengers. J Thorac CARDiovasc Surg 1986;91:290-99.

8. Reikeras O, Gunnes S, Ytrehus K, Norstrand K. Preservation of high energy phosphates during ischemic cardiac arrest with glucose. Scand J Thorac Cardiovasc Surg 1987;21:169-78.

9. Crestanello JA, Kamelgard J, Whitman GJ. The mechanism by which pyruvate protects myocardium from ischemia reperfusion injury: a dual mechanism. Surg Forum 1994;45:232-4.

10. Crestanello JA, Kamelgard J, Whitman GJ. The cumulative nature of pyruvate's dual mechanism for myocardial protection. J Surg Res 1995;59:198-204.

11. Crane F, Sun L, Sun E. The essential functions of coenzyme Q. Clin Invest 1993;71:(Suppl) 55-9.

12. Greenberg S, Frishman W. Coenzyme Q10: a new drug for cardiovascular disease. J Clin Pharmacol 1990;30:596-608.

13. Lenaz G, Fato R, Castelluccio C, et al. The functions of coenzyme $\mathrm{Q}$ in the mitochondria. Clin Invest 1993;71(Suppl):66-70.

14. Mitchell $P$. The vital protonmotive role of coenzyme Q. In: Folkers K, Littarru G, Yamagami Y, eds. Biomedical and clinical aspects of $\mathrm{CoQ}$, vol 6. Amsterdam: Elsevier, 1991:3-10.

15. Lenaz G, Battino M, Castelluccio C, et al. Studies of the role of ubiquinone in the control of the mitochondrial respiratory chain. Free Radic Res Comm 1990; 8:317-27.

16. Battino M, Fato R, Parenti-Castelli G, Lenaz G. Coenzyme $Q$ can control the efficiency of oxidative phosphorylation. Int J Tissue React 1990;12:137-44.

17. Ernster L, Forsmark P. Ubiquinol: an endogenous antioxidant in aerobic organisms. Clin Invest 1993; 71(Suppl):60-5.
18. Frei B, Kim M, Ames B. Ubiquinol 10 is an effective lipid soluble antioxidant at physiological concentrations. Proc Natl Acad Sci USA 1987;87:4879-83.

19. Beyer R. An analysis of coenzyme $Q$ in free radical generation and as an antioxidant. Biochem Cell Biol 1992;70:390-403.

20. Mortensen SA. Perspectives on therapy of cardiovascular diseases with coenzyme Q 10 (ubiquinone). Clin Invest 1993;71(Suppl):116-23.

21. Rengo F, Abete P, Landini P, et al. Role of metabolic therapy in cardiovascular disease. Clin Invest 1993; 71(Suppl):124-8.

22. Nayler WG. The use of coenzyme Q10 to protect ischemic heart muscle. In: Yakamura Y, Folkers K, Iti $\mathrm{Y}$, eds. Biomedical and clinical aspects of $\mathrm{CoQ}$, vol 2. Amsterdam: Elsevier, 1980:409-25.

23. Bessman S, Carpenter L. The creatine phosphate energy shuttle. Annu Rev Biochem 1985;54:831-62.

24. Kaplan L, Blum H, Banerjee A, Whitman GJ. Protecting myocardial creatine kinase activity during reperfusion improves bioenergetics and contractile function. J Surg Res 1993;54:311-5.

25. Edlund PO. Determination of $\mathrm{CoO}$, alfa-tocopherol and cholesterol in biological samples by coupledcolumn liquid chromatography with coulorimetric and ultraviolet detection. J Chromatogr 1988;425:87-97.

26. Kitai T, Tanaka A, Terasaki M, et al. Energy metabolism of the heart and the liver in brain dead dogs as assessed by 31P NMR spectroscopy. J Surg Res 1993;55:599-606.

27. Moon RB, Richards JH. Determination of intracellular $\mathrm{pH}$ by $31 \mathrm{P}$ magnetic resonance. J Biol Chem 1973;248:7276-8.

28. Nakamura T, Samma H, Himeno M, Kato K. Transfer of exogenous coenzyme $\mathrm{Q}$ to the inner membrane of hearts mitochondria in rats. In: Yakamura Y, Folkers $\mathrm{K}$, Iti Y. eds. Biomedical and clinical aspects of CoQ, vol 2. Amsterdam: Elsevier, 1980:3-14.

29. Hano O, Thompson-Gorman S, Zweier J, Lakatta G. Coenzyme Q10 enhances cardiac functional and metabolic recovery and reduces Ca overload during postischemic reperfusion. Am J Physiol 1994;266:H2174-81.

30. Sugawara H, Yamamoto T, Scimizu SI, et al. Inhibition of ubiquinone synthesis in isolated rat heart under ischemic condition. Int J Biochem 1990;22:477-80.

31. Judy WV, Stogsdill WW, Folkers K. Myocardial preservation with coenzyme $\mathrm{Q}_{10}$ during heart surgery. Clin Invest 1993;71:S155-61.

32. Muscari C, Magnani B, Biagette L, et al. Protective effects of coenzyme $Q_{10}$ administration and relationship with its reduced biosynthesis in the ischemic and reperfused myocardium. In: Folkers K, Littarru GP, Yamagami T, eds. Biomedical and clinical aspects of coenzyme $Q_{10}$. Vol 6. Amsterdam: Elsevier, 1991:30110.

33. Okamoto F, Allen BS, Buckberg GD. Reperfusion 
composition: supplemental role of intravenous and intracoronary coenzyme $\mathrm{Q}_{10}$ in avoiding reperfusion damage. J Thorac Cardiovasc Surg 1983;86:262-72.

34. Laster S, Becker L, Ambrosio G, Jacobus W. Reduced aerobic metabolic efficiency in globally stunned myocardium. J Mol Cell Cardiol 1989;21:419-26.

35. Ohgoshi Y, Goto Y, Futaki S, Yaku H, Kawaguchi O, Suga H. Increased oxygen cost of contractility in stunned myocardium of dog. Circ Res 1991;69:975-88.

36. Bavaria JE, Furukawa S, Kreiner G, et al. Thorac Cardiovasc Surg 1990;100:210-20.

37. Dean EN, Shlafer M, Nicklas JM. The oxygen consumption paradox of stunned myocardium in dogs. Basic Res Cardiol 1990;85:120-31.

38. Piper H, Noll T, Siegmund B. Mitochondrial function in the oxygen depleted and reoxygenated myocardial cell. Cardiovasc Res 1994;28:1-15.

39. Flameng W, Andres J, Ferdinande P, Mattheussen M, Van Belle H. Mitochondrial function in myocardial stunning. J Mol Cell Cardiol 1991;23:1-11.

40. Asimakis GK, Zwischenberger JB, Inners-McBride $\mathrm{K}$, Sordahl LA, Conti VR. Post ischemic recovery of mitochondrial adenine nucleotides in the heart. Circulation 1992;85:2212-20.

41. Bolling S, Olszanski B, Childs K, Gallagher K, Ning $\mathrm{X}$. Stunning, preconditioning, and functional recovery after global myocardial ischemia. Ann Thorac Surg 1994;58:822-7.

42. Murry CE. A mechanism of myocardial stunning. Circulation 1990;82:723-38.

43. Poole-Wilson P, Holmberg S, Williams A. A possible molecular mechanism for stunning of the myocardium. Eur Heart J 1991;12(Suppl):25-9.

44. Braunwald E. Stunning of the myocardium: an update. Cardiovasc Drugs Ther 1991;5:849-51.

45. Ambrosio G, Jacobus WE, Mitchell MC, Litt MR, Becker LC. Effects of ATP precursors and free ADP content and functional recovery of postischemic hearts. Am J Physiol 1989;256:H560-6.

46. Auchampach JA, Maruyama M, Cavero I, Gross GJ. Pharmacological evidence for a role of ATP-dependent potassium channels in myocardial stunning. Circulation 1992;86:311-9.

\section{Discussion}

Dr. Pedro J. del Nido (Boston, Mass.). I congratulate you on an elegant study and thank you for sending me the manuscript ahead of time.

This is an important mechanism that you have outlined here, and one that has been studied by several investigators in the past. All have also demonstrated that $\mathrm{CoQ}_{10}$ is very effective, with both experimental studies and, I may now add, human data showing that it may in fact be useful. The important aspect of your study is that you have convincingly demonstrated that the mechanism may in fact be its antioxidant protection of CK. One of the major effects of the presence of CK is to lower free ATP levels; the free energy of ATP hydrolysis, which is required to drive the calcium pumps, is thus preserved.

You have available, however, a means of measuring the activity of $\mathrm{CK}$ in vivo by performing saturation transfer experiments with NMR and measuring the free energy of ATP hydrolysis. Have you done those experiments to corroborate the in vitro assays of CK enzyme activity?

Second, with respect to the question of whether the $\mathrm{COQ}_{10}$ is actually used, have you looked at UBIQUINOL levels in these hearts after administration?

Dr. Crestanello. We have not looked at CK activity through saturation transfer or looked at the free energy of ATP hydrolysis in this animal model, but we have plans to do that.

Regarding your second question on the UBIQUINOL levels in the heart, we measured them. Those are the levels that we have shown as the levels of $\mathrm{CoQ}_{10}$ in the myocardium.

Dr. Michael A. Rowland (Melboume, Australia). I commend you for tackling the difficult question of the mechanism of action of this important and interesting compound. The improved postischemic $\mathrm{DP} / \mathrm{MVO}_{2}$, higher ATP and phosphocreatine levels, and preservation of CK activity are all indicative of a myoprotective effect. You would expect to see these with other forms of protection, such as hypothermia or cardioplegia, and they are not specific to $\mathrm{CoQ}_{10}$.

The mechanism of this effect probably relates to $\mathrm{CoQ}_{10}$ as a potent free radical scavenger, which brings me to my first question. Did you measure indexes of oxidative stress such as thiobarbituric acid-reactive substances or reduced oxidized glutathione ratio? If so, was there a difference between the two groups?

Second, I was interested to see the elevated levels of phosphocreatine and ATP in prestress measurements of the treated group. Does this represent a supernormal level of high-energy phosphates, or is this a reflection of the myoprotective effects of $\mathrm{CoQ}_{10}$ against the insult to the heart of the setting and preparation?

Finally, we believe that another protective action of $\mathrm{COQ}_{10}$ may play an important role, particularly in the senescent myocardium. The unique position of $\mathrm{CoQ}_{10}$ as a mobile electron carrier within the mitochondrial membrane enables it to maintain the flow of energy and sustain ATP production in the face of both acute and chronic free radical injury to the mitochondrial membrane and the protein complexes. To what extent do you think that this mechanism could be operational in your model?

Dr. Crestanello. Regarding your first question, if we have looked at other ways to measure oxidative stress in our model, we have used lucigenin-enhanced chemiluminescence to continuously and directly measure free oxygen radical production. We have shown that hearts pretreated with $\mathrm{CoQ}_{10}$ had lower levels of oxidative stress than control hearts.

Regarding your second question about the higher levels of high-energy phosphates at equilibration before the ischemic insult, we attribute this effect of $\mathrm{CoQ}_{10}$ to the improvement in oxidative phosphorylation and respiratory chain efficiency. Regarding your last question, I agree that the last mechanism you outlined is very important, and it could also explain our results. 